\title{
Effect of Limb Ischemic Preconditioning on Myocardial Injury in Patients Undergoing Mitral Valve Replacement Surgery - A Randomized Controlled Trial -
}

Qingping Wu, PhD; Ping Gui, MD; Jing Wu, MD; Defang Ding, MD; Gunsham Purusram, MD; Nianguo Dong, PhD; Shanglong Yao, PhD

\begin{abstract}
Background: Whether limb ischemic preconditioning (LIPC) is beneficial for patients undergoing mitral valve replacement (MVR) surgery is unknown.

Methods and Results: Seventy-five adult patients undergoing MVR surgery were randomly assigned to 3 groups: control group ( $n=25)$, LIPC group I $(3 \times 5$-min cycles of right upper arm ischemia and 5-min reperfusion; $n=25)$ and LIPC group II $(3 \times 5$-min cycles of right upper arm ischemia and 5 -min reperfusion combined with $2 \times 10$-min cycles of right upper leg ischemia and 10-min reperfusion; $n=25)$. Cardiopulmonary bypass (CPB) time, cross-clamp time, cardiac index, cumulative postoperative dosage of dobutamine, intensive care stay, postoperative hospital stay were not statistically different. Although the cumulative postoperative dosage of dobutamine was not different, there was a significantly lower inotropic requirement in LIPC II compared with the control group at 4 and $8 \mathrm{~h}$ after surgery. Plasma levels of cardiac troponin-I in the 3 groups significantly increased during CPB and peaked at $4 \mathrm{~h}$ after surgery. Levels of CTnI in LIPC II were significantly lower than in the control group at each time point after surgery.
\end{abstract}

Conclusions: Myocardial injury is obvious after MVR surgery. LIPC can protect the myocardium from ischemiareperfusion injury and decrease the inotropic requirement after surgery. The data also confirmed the requirement for the preconditioning stimulus to cross a threshold. (Circ $J$ 2011; 75: 1885-1889)

Key Words: Limb ischemic preconditioning; Mitral valve replacement surgery; Myocardial injury

$\mathbf{S}$ udies have found that a preconditioning stimulus can have systemic effects that protect distant tissues from subsequent ischemia, and this variant is called remote ischemic preconditioning (RIPC). RIPC is mostly carried out as limb ischemic preconditioning (LIPC), because it is feasible and achievable. A series of animal studies have shown that LIPC protects the heart, ${ }^{1}$ lungs, ${ }^{2}$ liver,${ }^{3}$ brain ${ }^{4}$ and spinal $\operatorname{cord}^{5}$ from ischemia-reperfusion injury (IRI). Human studies have confirmed that LIPC can reduce the occurrence of IRinduced vascular endothelial cell dysfunction ${ }^{6,7}$ and lower the IR-induced leukocyte activation. ${ }^{8}$ Furthermore, it has been used to attenuate myocardial injury in children undergoing corrective cardiac surgery for congenital heart disease, ${ }^{9}$ in coronary artery bypass graft surgery ${ }^{10}$ and in elective abdominal aortic aneurysm repair surgery. ${ }^{11}$

\section{Editorial $p 1821$}

In this study, we investigated the effect of different methods of LIPC on myocardial injury in patients undergoing mitral valve replacement (MVR) surgery.

\section{Methods}

\section{Patient Population}

The study was approved by the Ethics Committee of Tongji Medical College of Huazhong University of Science and Technology. We undertook a randomized, controlled prospective study from June 1, 2009 to January 31, 2010 at Union Hospital. Written informed consent was obtained before enroll-

Received November 9, 2010; revised manuscript received March 22, 2011; accepted April 5, 2011; released online June 21, 2011 Time for primary review: 21 days

Department of Anesthesiology (Q.W., P.G., J.W., D.D., G.P., S.Y.), Department of Cardiovascular Surgery (N.D.), Union Hospital, Tongji Medical College, Huazhong University of Science and Technology, Wuhan, China

Grant: This study is supported by a grant (No. 30801076) from the National Natural Science Foundation of China.

Mailing address: Shanglong Yao, PhD, Department of Anesthesiology, Union Hospital, Tongji Medical College, Huazhong University of Science and Technology, 1277\# Jiefang Da Dao, Wuhan 430022, China. E-mail: yao_shanglong@126.com

ISSN-1346-9843 doi:10.1253/circj.CJ-10-1130

All rights are reserved to the Japanese Circulation Society. For permissions, please e-mail: cj@j-circ.or.jp 


\begin{tabular}{lccc|}
\hline Table 1. Patients' Characteristics & & & \\
Age (years) & Control $(\mathbf{n}=\mathbf{2 5})$ & LIPC I (n=25) & LIPC II (n=25) \\
Female & $43.6 \pm 14.3$ & $46.2 \pm 12.2$ & $44.9 \pm 14.4$ \\
Male & $18 / 25$ & $15 / 25$ & $16 / 25$ \\
Weight (kg) & $7 / 25$ & $10 / 25$ & $9 / 25$ \\
Mitral valve disease & $59.3 \pm 8.4$ & $58.8 \pm 6.4$ & $55.5 \pm 13.1$ \\
$\quad$ Stenosis & & & \\
Regurgitation & $4 / 25$ & $3 / 25$ & $3 / 25$ \\
$\quad$ Stenosis combined regurgitation & $2 / 25$ & $3 / 25$ & $4 / 25$ \\
Etiology & $19 / 25$ & $19 / 25$ & $18 / 25$ \\
$\quad$ Rheumatic heart disease & & & \\
Degenerative valvular heart disease & $22 / 25$ & $24 / 25$ & $24 / 25$ \\
EF (\%) & $3 / 25$ & $1 / 25$ & $1 / 25$ \\
Cardiac function (NYHA) & $63.4 \pm 7.0$ & $62.3 \pm 6.4$ & $61.1 \pm 8.0$ \\
II & & & $15 / 25$ \\
III & $16 / 25$ & $15 / 25$ & $10 / 25$ \\
Prosthesis & $9 / 25$ & $10 / 25$ & $1 / 25$ \\
$\quad$ Bioprosthesis & & & $24 / 25$ \\
Mechanical prosthesis & $3 / 25$ & $1 / 25$ & $9 / 25$ \\
Concomitant tricuspid valvuloplasty & $22 / 25$ & $24 / 25$ & $0 / 25$ \\
Mitral valve repair & $10 / 25$ & $8 / 25$ & $0 / 25$ \\
\hline
\end{tabular}

Data are mean \pm SD.

LIPC, limb ischemic preconditioning; EF, ejection fraction; NYHA, New York Heart Association.

ment in the study. Patients (aged 18-60 years) undergoing MVR surgery were eligible for inclusion. Exclusion criteria included other heart abnormalities; New York Heart Association class IV; history of respiratory infection, asthma or cardiac surgery; hepatic, renal, or pulmonary disease; peripheral vascular disease affecting limbs; and patients taking the antidiabetic sulfonylurea, glibenclamide, because this agent has been shown in experimental studies to abrogate the cardioprotection elicited by ischemic preconditioning. ${ }^{12}$ Patients were randomly assigned to 3 groups before MVR surgery: control group $(n=25)$, LIPC group I $(n=25)$ and LIPC group II $(\mathrm{n}=25)$.

\section{LIPC Protocol}

LIPC consisted of $3 \times 5$-min cycles of right upper arm ischemia and 5-min reperfusion in LIPC I, and 3×5-min cycles of the right upper arm ischemia and 5-min reperfusion combined with $2 \times 10$-min cycles of right upper leg ischemia and 10-min reperfusion in LIPC II. Limb ischemia was induced by an automated cuff-inflator either placed on the right upper arm and inflated to $200 \mathrm{mmHg}$ or placed on the right upper leg and inflated to $450 \mathrm{mmHg}$. Control patients had a deflated cuff placed on the right upper arm for $30 \mathrm{~min}$. LIPC was performed after anesthesia induction and before surgery started.

\section{Anesthetic Technique and Cardiopulmonary Bypass (CPB)}

Patients were premedicated with diazepam (10 mg IM) and scopolamine $(0.3 \mathrm{mg}$ IM) $30 \mathrm{~min}$ before surgery. On arrival in the anesthetic room, a peripheral venous cannula was inserted and lactated Ringer's solution was infused. An arterial cannula was inserted before anesthesia and arterial pressure was continuously monitored. Anesthesia was induced with midazolam $(0.05-0.1 \mathrm{mg} / \mathrm{kg})$, fentanyl $(10-20 \mu \mathrm{g} / \mathrm{kg})$, and vecuronium $(0.1 \mathrm{mg} / \mathrm{kg})$. The trachea was intubated and mechanical ventilation with $100 \%$ oxygen was begun. Blood gas analysis was performed to adjust the tidal volume to main- tain normal arterial carbon dioxide. Anesthesia was maintained with intravenous administration of midazolam $(0.1 \mathrm{mg}$. $\left.\mathrm{kg}^{-1} \cdot \mathrm{h}^{-1}\right)$, sufentanyl $\left(2.0-3.0 \mu \mathrm{g} \cdot \mathrm{kg}^{-1} \cdot \mathrm{h}^{-1}\right)$ and vecuronium $\left(0.1 \mathrm{mg} \cdot \mathrm{kg}^{-1} \cdot \mathrm{h}^{-1}\right)$. Central venous catheter was inserted in the right internal jugular vein after intubation.

The CPB circuit included a membrane oxygenator and a roller pump system. ${ }^{13}$ The pump priming solution consisted of sufficient crystalloid and $20 \%$ albumin to keep the hematocrit value between $25 \%$ and $30 \%$. Anticoagulation was accomplished by intravenous administration of heparin sulfate, which was neutralized with protamine sulfate at the end of CPB. Cannulation was accomplished using the ascending aorta for inflow and the inferior and superior venae cavae for the outflow. Cardiac arrest was accomplished by aortic cross clamping coupled with infusion of high-potassium blood cardioplegic solution $\left(4-7^{\circ} \mathrm{C},\left[\mathrm{K}^{+}\right] 20 \mathrm{mmol} / \mathrm{L}\right)$ through the aortic root. Cardioplegic solution was given intermittently and the average interval was $30 \mathrm{~min}$. Retrograde cardioplegia was not used in any case. Mild systemic hypothermia (temperature $>28^{\circ} \mathrm{C}$ and $<32^{\circ} \mathrm{C}$ ) was maintained during aortic cross-clamping. ${ }^{14}$ When suturing the valve was almost completed, patients were slowly rewarmed. The atrial septum and the heart were closed, deaired, and the aortic clamp was removed. Warm blood cardioplegic solution was not given before removing the aortic clamp. Hemodynamics had to be stable before weaning from bypass. Blood gas management during CPB was directed towards maintenance of homeostasis.

\section{Clinical Observation Indices}

CPB time, cross-clamp time, cardiac index (CI), inotropic requirement, intensive care stay, and postoperative stay in hospital were recorded. The latter 3 indices were recorded in the intensive care unit by nurses who were not involved in the study and were unaware of the grouping. Postoperative arterial pressure-based cardiac output was measured by the FloTrac/Vigileo system (Edwards Lifesciences, Irvine, CA, 


$\begin{array}{lccc}\text { Table 2. Clinical Observation Indicesexes } & & & \\ & \text { Control } & \text { LIPC I } & \text { LIPC II } \\ \text { CPB time (min) } & 82.1 \pm 8.3 & 90.0 \pm 25.4 & 92.1 \pm 24.4 \\ \text { Cross-clamp time (min) } & 51.7 \pm 7.4 & 59.3 \pm 19.8 & 63.5 \pm 19.8 \\ \text { Cumulative postoperative dosage of dobutamine }(\mathrm{mg}) & 417.3 \pm 137.8 & 401.3 \pm 164.2 & 392.2 \pm 118.0 \\ \text { Intensive care stay (h) } & 68.5 \pm 8.2 & 71.4 \pm 16.4 & 73.0 \pm 11.6 \\ \text { Postoperative hospital stay (days) } & 12.4 \pm 2.8 & 12.1 \pm 2.6 & 11.7 \pm 2.0\end{array}$

Data are mean \pm SD.

LIPC, limb ischemic preconditioning; CPB, cardiopulmonary bypass.

Table 3. Inotropic Requirement and Cl

\begin{tabular}{|c|c|c|c|c|c|c|}
\hline & \multicolumn{3}{|c|}{ Inotropic requirement $\left(\mu \mathrm{g} \cdot \mathrm{kg}^{-1} \cdot \mathrm{min}^{-1}\right)$} & \multicolumn{3}{|c|}{$\mathrm{Cl}\left(\mathrm{L} \cdot \mathrm{min}^{-1} \cdot \mathrm{m}^{-2}\right)$} \\
\hline & Control & LIPC I & LIPC II & Control & LIPC I & LIPC II \\
\hline T2 & $2.1 \pm 4.7$ & $12.0 \pm 4.4$ & $11.6 \pm 4.8$ & $2.1 \pm 0.2$ & $2.2 \pm 0.3$ & $1.9 \pm 0.2$ \\
\hline T3 & $11.2 \pm 4.5$ & $10.8 \pm 3.7$ & $8.1 \pm 4.0^{*}$ & $2.5 \pm 0.2$ & $2.4 \pm 0.3$ & $2.6 \pm 0.3$ \\
\hline $\mathrm{T} 4$ & $10.8 \pm 3.6$ & $11.0 \pm 2.9$ & $7.5 \pm 4.2^{*}$ & $2.6 \pm 0.1$ & $2.5 \pm 0.3$ & $2.7 \pm 0.2$ \\
\hline T5 & $8.4 \pm 3.8$ & $8.6 \pm 3.1$ & $7.2 \pm 3.2$ & $2.9 \pm 0.3$ & $2.8 \pm 0.2$ & $2.8 \pm 0.2$ \\
\hline T6 & $6.9 \pm 3.0$ & $6.6 \pm 2.6$ & $7.1 \pm 2.8$ & $2.8 \pm 0.2$ & $2.6 \pm 0.3$ & $2.7 \pm 0.2$ \\
\hline T7 & $4.5 \pm 1.9$ & $4.6 \pm 1.8$ & $4.8 \pm 2.4$ & $2.7 \pm 0.1$ & $2.8 \pm 0.2$ & $2.9 \pm 0.2$ \\
\hline
\end{tabular}

Data are mean \pm SD. ${ }^{*} P<0.05$ vs. control group.

$\mathrm{Cl}$, cardiac index; LIPC, limb ischemic preconditioning; T2, end of surgery; T3, 4h after surgery; T4, 8h after surgery; $\mathrm{T} 5,12 \mathrm{~h}$ after surgery; T6, $24 \mathrm{~h}$ after surgery; T7, $48 \mathrm{~h}$ after surgery.

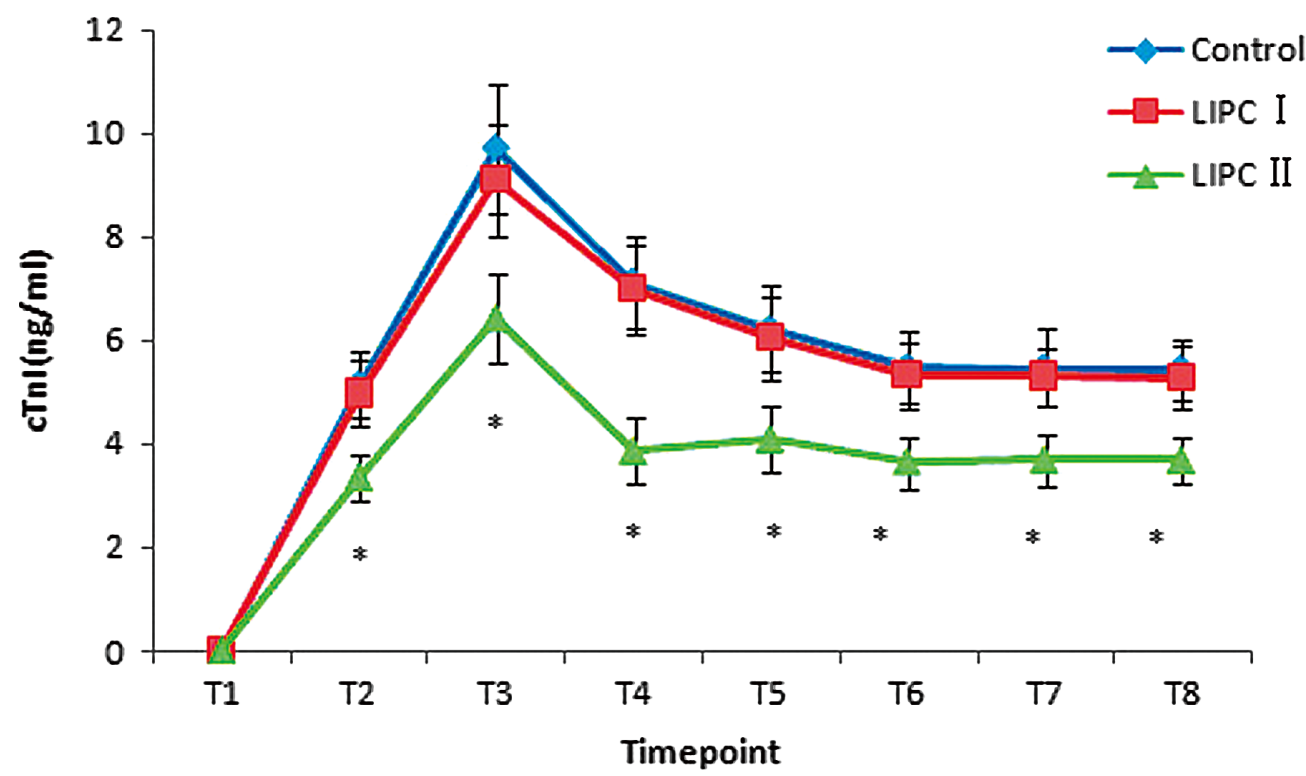

Figure. Changes in the plasma levels of cardiac troponin I (cTnl) in the 3 groups. Data are mean $\pm S D$. ${ }^{*} P<0.05$ vs. the control group. T1, before surgery; T2, end of surgery; T3, $4 \mathrm{~h}$ after surgery; T4, $8 \mathrm{~h}$ after surgery; $\mathrm{T} 5,12 \mathrm{~h}$ after surgery; T6, $24 \mathrm{~h}$ after surgery; T7, 48 h after surgery; T8, 72 h after surgery. LIPC, limb ischemic preconditioning.

USA). ${ }^{15}$ Dobutamine was administered for low cardiac output $\left(\mathrm{CI}<2.0 \mathrm{~L} \cdot \mathrm{min}^{-1} \cdot \mathrm{m}^{-2}\right)$.

\section{Blood Analysis}

Blood samples for measurement of cardiac troponin I (cTnI) were collected from the arterial cannula before surgery and immediately, 4, 8, 12, 24, 48, and 72h after surgery. Blood gas analysis was done and hematocrit was recorded at each time point. Plasma was obtained by centrifugation at 4,000 rpm for $15 \mathrm{~min}$ and then stored at $-20^{\circ} \mathrm{C}$. Plasma cTnI concentrations were analyzed by Abbott automatic biochemistry analyzer with matching kits within 5 days of collecting the samples. The correction value of cTnI was obtained according to the formula: correction value of $\mathrm{cTnI}=$ (preoperative hematocrit value $\times$ cTnI value)/sampling hematocrit value. 


\section{Statistical Analysis}

Data are expressed as mean \pm SD and were analyzed by SPSS software (SPSS Inc, Chicago, IL, USA). All categorical variables were tested by chi-square test. All normally distributed data (tested by Kolmogorov-Smirnov test) were analyzed using Student's t-test. Repeated measures were analyzed using 1 - and 2-way analysis of variance. $\mathrm{P}<0.05$ was considered statistically significant.

\section{Results}

\section{Patients' Characteristics}

Distribution of age, weight, sex, type and etiology of mitral valve disease, ejection fraction, preoperative cardiac functional grading, prosthesis used and surgical procedure were not statistically different among the 3 groups (Table 1). There were no operative deaths or serious complications in any group. Data for the 3 groups were obtained under the same conditions and were comparable.

\section{Clinical Observation Indices}

CPB time, cross-clamp time, $\mathrm{CI}$, cumulative postoperative dosage of dobutamine, intensive care stay and postoperative hospital stay were not statistically different. Although the cumulative postoperative dosage of dobutamine was not different, there was a significantly lower inotropic requirement in LIPC II compared with the control group at 4 and $8 \mathrm{~h}$ after surgery (Tables 2,3).

\section{Measurement of cTnl}

Plasma levels of cTnI in the 3 groups significantly stepped up during CPB and peaked at $4 \mathrm{~h}$ after surgery. Levels of cTnI between the control and LIPC I groups were not statistically different, but levels of cTnI in LIPC I were relatively lower than the control group at each time point after surgery. Levels of cTnI in LIPC II were significantly lower than in the control group at each time point after surgery (Figure).

\section{Discussion}

In this study, increasing the intensity of LIPC, mediated by $3 \times 5$-min cycles of right upper arm ischemia and 5-min reperfusion combined with $2 \times 10$-min cycles of right upper leg ischemia and 10-min reperfusion, reduced the cTnI level in the perioperative period in patients undergoing MVR surgery and decreased the inotropic requirement after surgery.

At present, cTnI is considered to be one of the most specific and sensitive markers for the diagnosis and monitoring of acute myocardial infarction, unstable angina and perioperative myocardial injury. A series of studies confirmed the value of cTnI after cardiac surgery associated with shortand long-term complications. Vermes et al showed that cTnI could be a marker of myocardial ischemia after open heart surgery. ${ }^{16}$ Lasocki et al have shown that the cTnI concentration measured $20 \mathrm{~h}$ after the end of surgery is an independent predictor of in-hospital death after cardiac surgery, and elevated concentrations of cTnI were associated with both a cardiac cause of death and major postoperative complications. ${ }^{17}$ In our study, the plasma levels of cTnI in the control group significantly stepped up during CPB and reached their peak at $4 \mathrm{~h}$ after surgery, indicating obvious myocardial injury in patients undergoing MVR surgery. Levels of cTnI in LIPC II were significantly lower than in the control group at each time point after surgery, which suggests that increasing the intensity of LIPC can protect the myocardium from IRI in patients undergoing MVR surgery.

Our study also confirms the requirement for the preconditioning stimulus to cross a threshold. LIPC consisting of $3 \times$ 5 -min cycles of right upper arm ischemia and 5-min reperfusion in LIPC I did not significantly reduce cTnI compared with the control group, whereas when it consisted of $3 \times$ 5 -min cycles of right upper arm ischemia and 5-min reperfusion combined with $2 \times 10$-min cycles of right upper leg ischemia and 10-min reperfusion the cTnI level was reduced. Loukogeorgakis et al found that RIPC $(3 \times 5-\mathrm{min}$ cycles of arm ischemia and 5-min reperfusion or $3 \times 5$-min cycles of leg ischemia and 5-min reperfusion) immediately before IR preserved endothelial function, and that RIPC administered as 2 cycles was effective only when applied to the leg. ${ }^{18}$ Hausenloy et al showed that adult patients undergoing elective coronary artery bypass graft surgery at a single tertiary centre could benefit from RIPC using only $3 \times 5-$ min cycles of right upper limb IR. ${ }^{10}$ Why are our study results different from these previous studies? Compared with other studies, ours concentrated on patients undergoing MVR surgery, which has more chance of myocardial injury than do patients undergoing coronary artery bypass graft surgery, so more potent pretreatment was needed to obtain myocardial protection. Cheung et $\mathrm{al}^{9}$ demonstrated the myocardial protective effects of RIPC using a simple noninvasive technique of $4 \times$ 5-min cycles of lower limb ischemia and 5-min reperfusion. Postoperative levels of cTnI were greater in the control patients than in the RIPC group, indicating greater myocardial injury in the control patients. The postoperative inotropic requirement was greater in the control patients than in the RIPC patients at both 3 and $6 \mathrm{~h}\left(7.9 \pm 4.7 \mu \mathrm{g} \cdot \mathrm{kg}^{-1} \cdot \mathrm{min}^{-1}\right.$ vs. $10.9 \pm 3.2 \mu \mathrm{g} \cdot \mathrm{kg}^{-1} \cdot \mathrm{min}^{-1} ; 7.3 \pm 4.9 \mu \mathrm{g} \cdot \mathrm{kg}^{-1} \cdot \mathrm{min}^{-1}$ vs. $10.8 \pm$ $\left.3.9 \mu \mathrm{g} \cdot \mathrm{kg}^{-1} \cdot \mathrm{min}^{-1}\right)$.

In this study, CI, inotropic requirement, intensive care stay and postoperative hospital stay were used to evaluate postoperative recovery. ${ }^{19}$ Many factors influence with postoperative recovery, such as CPB time, cross-clamp time, surgical techniques, $\mathrm{CPB}$ mode etc. $\mathrm{CI}$, the cumulative postoperative dosage of dobutamine, intensive care stay and postoperative hospital stay were not statistically different. Although the cumulative postoperative dosage of dobutamine was not different, there was a significantly lower inotropic requirement in LIPC II compared with the control group at 4 and $8 \mathrm{~h}$ after surgery.

The actual mechanism by which RIPC protects the myocardium is unclear. Information transfer in RIPC may be mediated by humoral mediators or through a neurogenic path or a combination of both, and involves adenosine, ${ }^{20,21}$ opioids, ${ }^{22}$ bradykinins, ${ }^{23}$ protein kinase $\mathrm{C},{ }^{24}$ and ATP-sensitive potassium channels. ${ }^{18,25}$ Whatever the pathway, the basic mechanism of a preconditioning stimulus is the transfer and storage of information to prime signal pathways, which raises the threshold of cells to subsequent injury. As LIPC is a relatively more feasible and operable form of RIPC, exploring its protective effect has a strong clinical significance.

In short, our research suggests that myocardial injury in patients with MVR surgery is inevitable. LIPC can reduce the postoperative cTnI value and inotropic requirement to a certain extent, but it also should be noted that LIPC did not significantly reduce intensive care stay and postoperative hospital stay, and thus the protective effects of LIPC remain to be further researched. However, this study confirms the relationship between the protective effect and the preconditioning method, and provides a basis for developing a simpler and more effective method of preconditioning. 


\section{Acknowledgments}

This study was supported by Grant No. 30801076 from the National Natural Science Foundation of China. The authors thank Fen Xu (nurse Department of Cardiovascular Surgery, Union Hospital, Tongji Medical College, Huazhong University of Science and Technology, Wuhan, China) for recording clinical observation indices in the intensive care unit.

\section{References}

1. Andreka G, Vertesaljai M, SzanthoG, Font G, Piroth Z, Fontos G, et al. Remote ischaemic postconditioning protects the heart during acute myocardial infarction in pigs. Heart 2007; 93: 749-752.

2. Waldow T, Alexiou K, Witt W, Albrecht S, Wagner F, Knaut M, et al. Protection against acute porcine lung ischemia/reperfusion injury by systemic preconditioning via hind limb ischemia. Transplant Int 2005; 18: 198-205.

3. Gustafsson BI, Friman S, Wallin M, Heiman J, Delbro DS. Effect of remote preconditioning on mild or severe ischemia-reperfusion injury to rat liver. Transplant Proc 2006; 38: 2708-2709.

4. Sun XC, Li WB, Li QJ, Zhang M, Xian XH, Qi J, et al. Limb ischemic preconditioning induces brain ischemic tolerance via p38 MAPK. Brain Res 2006; 1084: 165-174.

5. Selimoglu O, Ugurlucan M, Basaran M, Gungor F, Banach M, $\mathrm{Cucu} \mathrm{O}$, et al. Efficacy of remote ischaemic preconditioning for spinal cord protection against ischaemic injury: Association with heat shock protein expression. Folia Neuropathol 2008; 46: $204-$ 212.

6. Kharbanda RK, Mortensen UM, White PA, Kristiansen SB, Schmidt MR, Hoschtitzky JA, et al. Transient limb ischemia induces remote ischemic preconditioning in vivo. Circulation 2002; 106: 2881 2883.

7. Loukogeorgakis SP, Panagiotidou AT, Broadhead MW, Donald A, Deanfield JE, MacAllister RJ. Remote ischemic preconditioning provides early and late protection against endothelial ischemia reperfusion injury in humans: Role of the autonomic nervous system. J Am Coll Cardiol 2005; 46: 450-456.

8. Konstantinov IE, Arab S, Kharbanda RK, Li J, Cheung MM, Cherepanov V, et al. The remote ischemic preconditioning stimulus modifies inflammatory gene expression in humans. Physiol Genomics 2004; 19: 143-150.

9. Cheung MM, Kharbanda RK, Konstantinov IE, Shimizu M, Frndova H, Li J, et al. Randomized controlled trial of the effects of remote ischemic preconditioning on children undergoing cardiac surgery: First clinical application in humans. J Am Coll Cardiol 2006; 47: 2277-2282.

10. Hausenloy DJ, Mwamure PK, Venugopal V, Harris J, Barnard M, Grundy E, et al. Effect of remote ischaemic preconditioning on myocardial injury in patients undergoing coronary artery bypass graft surgery: A randomized controlled trial. Lancet 2007; 370: $575-579$.

11. Ali ZA, Callaghan CJ, Lim E, Ali AA, Nouraei SA, Akthar AM, et al. Remote ischemic preconditioning reduces myocardial and renal injury after elective abdominal aortic aneurysm repair: A random- ized controlled trial. Circulation 2007; 116: I98-I105.

12. Mocanu MM, Maddock HL, Baxter GF, Lawrence CL, Standen NB, Yellon DM. Glimepiride, a novel sulfonylurea, does not abolish myocardial protection afforded by either ischemic preconditioning or diazoxide. Circulation 2001; 103: 3111-3116.

13. Honjo O, Osaki S, Kotani Y, Akagi T, Sano S. Diagnosis-based differences in response of global ventricular performance to modified ultrafiltration in children. Circ J 2010; 74: 86-92.

14. Kim H, Park PW, Sung K, Lee YT, Jun TG, Kim WS, et al. Midterm results of the Cox maze III procedure combined with open mitral commissurotomy for the treatment of rheumatic mitral stenosis. Circ J 2010; 74: 1332-1338.

15. Pratt B, Roteliuk L, Hatib F, Frazier J, Wallen RD. Calculating arterial pressure-based cardiac output using a novel measurement and analysis method. Biomed Instrum Technol 2007; 41: 403-411.

16. Vermes E, Mesguich M, Houel R, Soustelle C, Le Besnerais P, Hillion ML, et al. Cardiac troponin I release after open heart surgery: A marker of myocardial protection? Ann Thorac Surg 2000; 70: $2087-2090$.

17. Lasocki S, Provenchère S, Bénessiano J, Vicaut E, Lecharny JB, Desmonts JM, et al. Cardiac troponin I is an independent predictor of in-hospital death after adult cardiac surgery. Anesthesiology 2002; 97: 405-411.

18. Loukogeorgakis SP, Williams R, Panagiotidou AT, Kolvekar SK, Donald A, Cole TJ, et al. Transient limb ischemia induces remote preconditioning and remote postconditioning in humans by a K(ATP)-channel dependent mechanism. Circulation 2007; 116: $1386-1395$.

19. Hata M, Suzuki M, Sezai A, Niino T, Yoshitake I, Unosawa S, et al. Outcome of less invasive proximal arch replacement with moderate hypothermic circulatory arrest followed by aggressive rapid re-warming in emergency surgery for type A acute aortic dissection. Circ J 2009; 73: 69-72.

20. Pell TJ, Baxter GF, Yellon DM, Drew GM. Renal ischemia preconditions myocardium: Role of adenosine receptors and ATP-sensitive potassium channels. Am J Physiol 1998; 275: H1542-H1547.

21. Takaoka A, Nakae I, Mitsunami K, Yabe T, Morikawa S, Inubushi $\mathrm{T}$, et al. Renal ischemia/reperfusion remotely improves myocardial energy metabolism during myocardial ischemia via adenosine receptors in rabbits: Effects of "remote preconditioning". $J \mathrm{Am}$ Coll Cardiol 1999; 33: 556-564.

22. Weinbrenner C, Schulze F, Sárváry L, Strasser RH. Remote preconditioning by infrarenal aortic occlusion is operative via delta1-opioid receptors and free radicals in vivo in the rat heart. Cardiovasc Res 2004; 61: 591-599.

23. Schoemaker RG, van Heijningen CL. Bradykinin mediates cardiac preconditioning at a distance. Am J Physiol Heart Circ Physiol 2000; 278: H1571-H1576.

24. Wolfrum S, Schneider K, Heidbreder M, Nienstedt J, Dominiak P, Dendorfer A. Remote preconditioning protects the heart by activating myocardial PKC epsilon-isoform. Cardiovasc Res 2002; 55: 583-589.

25. Yellon DM, Downey JM. Preconditioning the myocardium: From cellular physiology to clinical cardiology. Physiol Rev 2003; 83: $1113-1151$. 